\title{
Oligoarticular Still Disease
}

National Cancer Institute

\section{Source}

National Cancer Institute. Oligoarticular Still Disease. NCI Thesaurus. Code C61279.

Juvenile rheumatoid arthritis affecting four or fewer joints, usually asymmetrically. The most commonly affected joints are the knee, elbow, wrist, and ankle. 